\title{
Erratum to: Witnessing the first sign of retinitis pigmentosa onset in the allegedly normal eye of a case of unilateral RP: a 30-year follow-up
}

\author{
Mathieu Gauvin - Hadi Chakor • Robert K. Koenekoop • John M. Little • \\ Jean-Marc Lina $\cdot$ Pierre Lachapelle
}

Published online: 28 April 2016

(C) Springer-Verlag Berlin Heidelberg 2016

\section{Erratum to: Doc Ophthalmol DOI 10.1007/s10633-016-9537-y}

In the original publication of the article, third and fourth author names were incomplete. The correct names are given in this erratum. Also, the section "Statement of human rights" has to be removed.

The online version of the original article can be found under doi:10.1007/s10633-016-9537-y.

M. Gauvin · H. Chakor · R. K. Koenekoop ·

J. M. Little · P. Lachapelle (ه)

Department of Ophthalmology and Neurology-

Neurosurgery, McGill University - Montreal Children's

Hospital Research Institute, Montreal, QC, Canada

e-mail: Pierre.lachapelle@mcgill.ca

J.-M. Lina

Département de génie électrique, École de Technologie

Supérieur, Montreal, QC, Canada

J.-M. Lina

Centre de Recherches Mathématiques, Montreal, QC,

Canada

P. Lachapelle

Research Institute of the McGill University Health Centre,

1001 Boul. Décarie, Glen Site, Block E, Program Mail

Drop Point \#EM03211 - Office \#EM03238, Montreal,

QC H4A 3J1, Canada 